\title{
Reduced plantar sensation leads to heterogeneous reactions in plantar pressure distribution during normal walking
}

\author{
Justin S Lange*, Thomas L Milani \\ From 4th Congress of the International Foot and Ankle Biomechanics (i-FAB) Community \\ Busan, Korea. 8-11 April 2014
}

\section{Introduction}

Many studies have determined the influence of provoking reduced plantar foot sensitivity on plantar pressure distribution patterns during the roll-over process (ROP) [1-3], but differ considerably in their approaches and results. This raises the question of whether the method of provoking decreased plantar foot sensitivity is responsible for the different results or whether subjects respond so differently that there is no uniform ROP reaction.

Therefore, the aim of this study was to evaluate individual response patterns in the ROP after provoking reduced plantar foot sensitivity and to consider the homogeneity of this reaction pattern within the sample.

\section{Methods}

The plantar foot of 19 subjects was treated with EMLA ${ }^{\circledR}$ cream containing the active ingredients lidocaine and prilocaine $[4,5]$. For each subject, the plantar sensations of vibration and touch at heel, forefoot and hallux were measured before the intervention and at three intervals of 45 minutes ( +15 min measuring time). Thereby the active course of the cream was documented. Nine anatomical sub-areas were identified on the peak pressure footprint [6]. The average ROP of 10 steps was determined at each measurement. Regression analyses were used to estimate the relationships among sensation and ROP variables. Using data from a control group, 'clinical

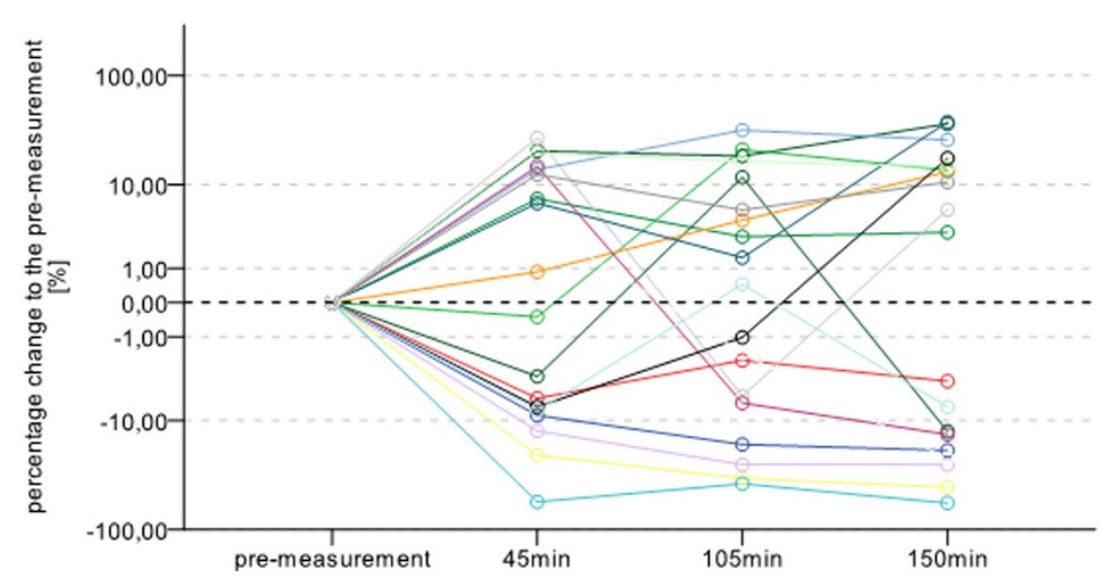

Figure 1 Percentage change of relative load under the first metatarsal head of each subject

* Correspondence: justin.lange@hsw.tu-chemnitz.de

Technische Universität Chemnitz, Chemnitz, Germany

(c) 2014 Lange and Milani; licensee BioMed Central Ltd. This is an Open Access article distributed under the terms of the Creative Commons Attribution License (http://creativecommons.org/licenses/by/4.0), which permits unrestricted use, distribution, and reproduction in any medium, provided the original work is properly cited. The Creative Commons Public Domain Dedication waiver (http://creativecommons.org/publicdomain/zero/1.0/) applies to the data made available in this article, unless otherwise stated. 
significance'[7] was used to evaluate individual subject reactions. A hierarchical cluster analysis was used to form groups with similar behaviour within the sample.

\section{Results}

Results showed strong interindividual differences in the process of sensation reduction over time. A linear relationship between change in sensory perceptions and plantar pressure variables was not detected. Nevertheless, the ROP results observed for each measurement differed strongly between and within subjects (e.g. Figure 1). Using cluster analysis, a group with a forefoot load increase was detected. Another group showed less variation in their forefoot pressure variables.

\section{Discussion}

The heterogeneity in the responses shows that subjects react differently when plantar foot sensitivity is perturbed by EMLA ${ }^{\circledR}$ cream. Thereby the ROP reaction seems to be not linear dependent from the level of reduction of plantar sensation. Indications for the existence of similar response patterns could be found despite the small sample size. In this study only a small time period of treatment was analysed. It remains unclear what would happen if plantar sensitivity was reduced for a longer period.

The complex interaction between the body, nervous system and environment may lead to various adaptive behaviours [8]. The idea of plasticity and modular control of locomotor patterns [9] could be useful for further interpretations.

Published: 8 April 2014

\section{References}

1. Nurse M, Nigg BM: The effect of changes in foot sensation on plantar pressure and muscle activity. Clinical Biomechanics 2001, 16:719-727.

2. Eils E, Nolte S, Tewes M, Thorwesten L, Völker K, Rosenbaum D: Modified pressure distribution patterns in walking following reduction of plantar sensation. Journal of biomechanics 2002, 35(10):1307-1313.

3. Höhne A, Stark C, Brüggemann GP: Plantar pressure distribution in gait is not affected by targeted reduced plantar cutaneous sensation. Clinical Biomechanics 2009, 24(3):308-313.

4. Wahlgren CF, Quiding H: Depth of cutaneous analgesia after application of a eutectic mixture of the local anesthetics lidocaine and prilocaine (EMLA cream). Journal of the American Academy of Dermatology 2000, 42(4):584-588.

5. McDonnell M, Warden-Flood A: Effect of partial foot anaesthesia on normal gait. Australian journal of physiotherapy 2000, 46(2):115-122.

6. Maiwald C, Grau S, Krauss I, Mauch M, Axmann D, Horstmann T: Reproducibility of plantar pressure distribution data in barefoot running. Journal of applied biomechanics 2008, 24:14-23.

7. Jacobson NS, Truax P: Clinical significance: a statistical approach to defining meaningful change in psychotherapy research. Journal of consulting and clinical psychology 1991, 59(1):12-19.

8. Chiel HJ, Beer RD: The brain has a body: adaptive behavior emerges from interactions of nervous system, body and environment. Trends in neurosciences 1997, 20(12):553-557.

9. Ivanenko YP, Cappellini G, Solopova IA, Grishin AA, MacLellan MJ, Poppele RE, Lacquaniti F: Plasticity and modular control of locomotor patterns in neurological disorders with motor deficits. Frontiers in computational neuroscience 2013, 7:123.

doi:10.1186/1757-1146-7-S1-A50

Cite this article as: Lange and Milani: Reduced plantar sensation leads to heterogeneous reactions in plantar pressure distribution during normal walking. Journal of Foot and Ankle Research 2014 7(Suppl 1):A50.

\section{Submit your next manuscript to BioMed Central and take full advantage of:}

- Convenient online submission

- Thorough peer review

- No space constraints or color figure charges

- Immediate publication on acceptance

- Inclusion in PubMed, CAS, Scopus and Google Scholar

- Research which is freely available for redistribution 